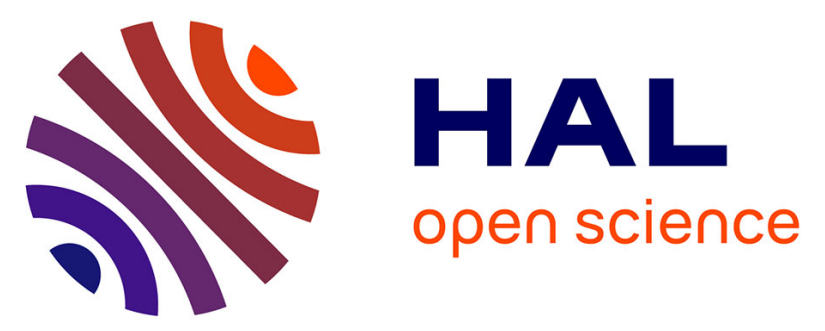

\title{
Mechanical Stress in InP Structures Etched in an Inductively Coupled Plasma Reactor with Ar/Cl-2/CH4 Plasma Chemistry
}

Jean-Pierre Landesman, Daniel T Cassidy, Marc Fouchier, Erwine Pargon, Christophe Levallois, Merwan Mokhtari, Juan Jiménez, Alfredo Torres

\section{To cite this version:}

Jean-Pierre Landesman, Daniel T Cassidy, Marc Fouchier, Erwine Pargon, Christophe Levallois, et al.. Mechanical Stress in InP Structures Etched in an Inductively Coupled Plasma Reactor with Ar/Cl2/CH4 Plasma Chemistry. Journal of Electronic Materials, 2018, Special Section: 17th Conference on Defects-Recognition, Imaging and Physics in Semiconductors (DRIP XVII), 47 (9), pp.4964-4969. 10.1007/s11664-018-6152-6 . hal-01861357

\section{HAL Id: hal-01861357}

\section{https://hal-univ-rennes1.archives-ouvertes.fr/hal-01861357}

Submitted on 10 Sep 2018

HAL is a multi-disciplinary open access archive for the deposit and dissemination of scientific research documents, whether they are published or not. The documents may come from teaching and research institutions in France or abroad, or from public or private research centers.
L'archive ouverte pluridisciplinaire HAL, est destinée au dépôt et à la diffusion de documents scientifiques de niveau recherche, publiés ou non, émanant des établissements d'enseignement et de recherche français ou étrangers, des laboratoires publics ou privés. 


\section{Mechanical Stress in InP Structures Etched in an Inductively Coupled Plasma Reactor with $\mathrm{Ar} / \mathrm{Cl}_{2} / \mathrm{CH}_{4}$ Plasma Chemistry}

JEAN-PIERRE LANDESMAN ${ }^{1,2}$, DANIEL T. CASSIDY ${ }^{2}$, MARC $^{\text {FOUCHIER }}{ }^{3}$, ERWINE PARGON ${ }^{3}$, CHRISTOPHE LEVALLOIS ${ }^{4}$, MERWAN MOKHTARI ${ }^{1}$, JUAN JIMENEZ ${ }^{5}$, and ALFREDO TORRES ${ }^{5}$

1.- Univ Rennes, CNRS, IPR - UMR 6251, F-35000 Rennes, France. 2.- McMaster University, Department of Engineering Physics, 1280 Main Street West, Hamilton, Ontario, L8S 4L7, Canada. 3.- Univ Grenoble Alpes, CNRS, LTM, F-38000 Grenoble, France. 4.- Univ Rennes, INSA Rennes, CNRS, Institut FOTON - UMR 6082, F-35000 Rennes, France. 5.- GdS Optronlab, Dpto. Fisica de la Materia Condensada, Universidad de Valladolid, 47011 Valladolid, Spain.

Corresponding author: JEAN-PIERRE LANDESMAN. e-mail : Jean-Pierre.Landesman@univ-rennes1.fr - Telephone: +33 223 233851 


\begin{abstract}
We investigate the crystal lattice deformation that can occur during the etching of structures in bulk InP using $\mathrm{SiN}_{\mathrm{x}}$ hard masks with $\mathrm{Ar} / \mathrm{Cl}_{2} / \mathrm{CH}_{4}$ chemistries in an inductively coupled plasma (ICP) reactor. Two techniques were used: degree of polarization (DOP) of the photo-luminescence (PL), which gives information on the state of mechanical stress present in the structures, and spectrally resolved cathodo-luminescence (CL) mapping. This second technique also provides elements on the mechanical stress in the samples through analysis of the spectral shift of the CL intrinsic emission lines. Preliminary DOP mapping experiments have been conducted on the $\mathrm{SiN}_{\mathrm{x}}$ hard mask patterns without etching the underlying InP. This preliminary study demonstrated the potential of DOP to map mechanical stress quantitatively in the structures. In a second step, InP patterns with various widths between 1 and $20 \mu \mathrm{m}$, and various depths between 1 and 6 $\mu \mathrm{m}$, were analyzed by the 2 techniques. DOP measurements were made both on the (100) top surface of the samples and on the (110) cleaved cross section. CL measurements were made only from the (100) surface. We observed that inside the etched features, close to the vertical etched walls, there is always some compressive deformation, while it is tensile just outside the etched features. The magnitude of these effects depends on the lateral and depth dimensions of the etched structures, and on the separation between them (the tensile deformation increases between them due to some kind of proximity effect when separation decreases).
\end{abstract}

Key words: indium phosphide, photonic devices, plasma etching, mechanical stress

\title{
INTRODUCTION
}

Plasma etching is broadly used nowadays in nanotechnology platforms, both in research, development and production, for the fabrication of a large number of components and integrated circuits. A good example of a family of such components is the photonic devices that can be fabricated on InP. One major drawback of plasma etching is the creation of structural and chemical damage in the vicinity of the etched surfaces. The defects introduced change the electrooptical properties of the semiconductor, thus ultimately compromising the device performance. Different studies have already reported on the damage created on flat surfaces exposed to reactive plasmas [1-3], either by identifying the structural and chemical defects, or by analyzing the changes in material electronic and optical properties due to damage. The degree of damage depends on the plasma etching parameters and notably it has been demonstrated that ion bombardment is mainly responsible for defect generation. Phenomena such as ion channeling combined with diffusion can create defects as deep as hundreds nm below the etched surface [4-7]. In GaAs etched with $\mathrm{SiCl}_{4}$ under a self-bias voltage of $80 \mathrm{~V}$ damage was found at depths of the order of $150 \mathrm{~nm}$ below the etched surface [7]. In a recent study, we have examined the impact of exposing InP materials, with InAsP quantum wells (QWs), to different etching plasmas based on chlorine, in inductively coupled plasma (ICP) reactors. We observed modifications of the QWs PL at depths up to $1 \mu \mathrm{m}$, even if the self-bias voltage is limited to less than $100 \mathrm{~V}$ [8]. Only a few studies have been dedicated to the plasma induced damage at the pattern sidewalls where the etching mechanisms are radically different from what happens on bottom surfaces. Indeed, the pattern sidewalls are subjected to a low ion flux at grazing incidence compared to flat surfaces that are exposed to a high ion flux at normal incidence. Moreover, sidewalls are often protected by passivation layers during the etching. This could play a role in the reduction of damage at the sidewalls by limiting radical diffusion or ion penetration [9]. There is clearly today a lack of knowledge on by which mechanisms and to what extent the plasma etching process induces damage at the III-V pattern sidewalls and the consequence it has on the device performance and the whole system functionality

We propose in this work to get some preliminary insights on the impact of plasma patterning on optical modifications of InP features. We focus on the lattice deformation that can occur during the etching of structures in bulk InP using chlorine chemistries in an ICP reactor. This deformation is measured and mapped using two complementary experimental techniques, degree of polarization (DOP) of the photo-luminescence (PL) and cathodo-luminescence (CL). Both techniques have already been used to map crystal deformations resulting from the presence of mechanical stresses in devices [10-12]. DOP is sensitive to non-biaxial deformations perpendicular to excitation beam propagation direction, whereas CL is sensitive mainly to the hydrostatic part of the deformation tensor, through the spectral shift of the emission band. Furthermore, both techniques have mapping capabilities, albeit different spatial resolution. Thus, if some local deformation results from the plasma processing of dedicated test features, the combination of the two techniques should first give us confidence in the identification of this deformation, and second provide a way to estimate quantitatively the different elements of the strain tensor.

\section{EXPERIMENTAL}

The samples for this study are etched in bulk InP (100) wafers (n-type, S-doped, $\mathrm{n}=1.8 \times 10^{18} \mathrm{~cm}^{-3}$ ) on which a $500 \mathrm{~nm}$ thick $\mathrm{SiN}_{\mathrm{x}}$ hard mask layer is realized by plasma enhanced chemical vapor deposition. The etched features are 
rectangular-shaped lines, having lateral dimension $\mathrm{L}=0.5,1,6,10$ and $20 \mu \mathrm{m}$, and aligned along the (110) direction of InP. These lines can be isolated, or grouped in series where the spacing between lines is $\mathrm{S}=0.5,1,2,3,6$ or $10 \mu \mathrm{m}$. After resist deposition, e-beam lithography, opening of this mask layer forming stripes (using a $\mathrm{CF}_{4} / \mathrm{CH}_{2} \mathrm{~F}_{2} / \mathrm{Ar}_{\mathrm{plasma}}$ ) and stripping of resist (using an $\mathrm{O}_{2}$ plasma), the $\mathrm{SiN}_{\mathrm{x}}$ patterns are transferred into the InP substrate. This is done with a $\mathrm{CH}_{4} / \mathrm{Cl}_{2} / \mathrm{Ar}$ plasma operated in an ICP reactor equipped with a hot cathode. During this step the samples are heated to a temperature of $200{ }^{\circ} \mathrm{C}$. The etch rate under the conditions of this study is approximately $900 \mathrm{~nm} / \mathrm{min}$. After etching, the $\mathrm{SiN}_{\mathrm{x}}$ hard mask and the passivation layers formed on the InP sidewalls are removed by a dual step cleaning procedure using $\mathrm{O}_{2}$ plasma followed by $49 \% \mathrm{HF}$ dip.

DOP characterization was performed using $633 \mathrm{~nm}$ laser excitation, at room temperature. Details on this technique can be found in [10] and [11]. We just recall here that the DOP signal measured along direction " $y$ " can be written as

$$
\mathrm{DOP}_{\mathrm{y}}=\frac{\mathrm{L}_{\mathrm{x}}-\mathrm{L}_{\mathrm{z}}}{\mathrm{L}_{\mathrm{x}}+\mathrm{L}_{\mathrm{z}}}=-\mathrm{C}_{\varepsilon}\left(\varepsilon_{\mathrm{xx}}-\varepsilon_{\mathrm{zz}}\right),(1)
$$

where $\mathrm{x}$ and $\mathrm{z}$ denote the 2 directions perpendicular to $\mathrm{y}$, and therefore belong to the plane of the surface being measured. $\mathrm{L}_{\mathrm{x}}$ and $\mathrm{L}_{\mathrm{z}}$ are the components of the spectrally-integrated PL with polarization along these 2 directions. $\varepsilon_{\mathrm{xx}}$ and $\varepsilon_{\mathrm{zz}}$ are the linear crystal deformations. $\mathrm{C}_{\varepsilon}$ is a calibration constant which has been determined experimentally for some InP surfaces [10]. Note that in all the figures discussed here $\mathrm{x}$ is the horizontal axis, $\mathrm{z}$ the vertical axis. As shown in [10], the sensitivity of the DOP technique is such that deformations of $10^{-5}$ can be detected. In addition to the term $\mathrm{DOP}_{\mathrm{y}}$, the measurements also yield the rotated DOP (ROP) defined by

$$
\mathrm{ROP}_{y}=\frac{\mathrm{L}_{\mathrm{x}^{\prime}}-\mathrm{L}_{\mathrm{z}^{\prime}}}{\mathrm{L}_{\mathrm{x}^{\prime}}+\mathrm{L}_{\mathrm{z}^{\prime}}}=2 \mathrm{C}_{\varepsilon} \varepsilon_{\mathrm{xz}},(2)
$$

where $x^{\prime}$ and $z^{\prime}$ are rotated by $45^{\circ}$ with respect to $x$ and $z .2 \varepsilon_{x z}$ is the angular deformation in the plane.

As an example, fig. 1 shows the output of a DOP measurement on the top surface of a sample with the $\mathrm{SiN}_{\mathrm{x}}$ mask stripes defined, just before the InP etching in the ICP reactor (isolated line with $\mathrm{L}=10 \mu \mathrm{m}$ ).

CL mapping was performed with a beam voltage of $5 \mathrm{kV}$, at room temperature. In the present study, we will only discuss the spectral shifts of the CL intrinsic band associated with band to band transitions. These shifts are related to the hydrostatic part of the crystal deformation, as the spectral resolution does not allow for the separation of different contributions which would result from non-equivalent deformations in the 3 directions [12]. Under this assumption, the CL peak shifts $\Delta \mathrm{E}_{\mathrm{CL}}$ may be related to the hydrostatic part of the stress tensor through the formula:

$$
\Delta \mathrm{E}_{\mathrm{CL}}=\mathrm{k} \cdot\left(\sigma_{\mathrm{xx}}+\sigma_{\mathrm{yy}}+\sigma_{\mathrm{zz}}\right) \text {, (3) }
$$

where the constant $\mathrm{k}$ has been calculated to be $-11.10^{-8} \mathrm{meV} / \mathrm{Pa}$ in the case of InP [13]. Note that a positive energy shift is associated to a compressive stress.

Fig. 2 shows two CL spectra, measured respectively on a raw wafer that will be used as a deformation-free reference and in the center of an etched line $(\mathrm{L}=1 \mu \mathrm{m})$. For the determination of the spectral shifts, we use a simple procedure where the central part of the band is fitted by a Gaussian profile. This procedure yields an accuracy of around $1 \mathrm{meV}$ for the determination of the spectral shifts.

\section{RESULTS AND DISCUSSION}

When discussing mechanical stress, it is always useful to start from a reference for which the stress profile is known. In our case, the reference state consists of the sample with the $\mathrm{SiN}_{\mathrm{x}}$ hard mask that has been opened to define the features to be etched, without having been transferred into the InP substrate. The situation in terms of the mechanical stress in such samples has been amply described in the literature $[14,15]$. The distribution of the mechanical stress induced by dielectric stripes at semiconductor surfaces has also been measured, essentially by micro-Raman spectroscopy [16]. On fig. 1 we can see that the DOP is positive inside the stripe, with a pronounced maximum value of around $2 \%$ close to the edges. The ROP is uniform and negligible (within the limit of the instrument resolution). The total PL yield shows a minimum below the stripe. To better view the DOP variation, we averaged the DOP map in the vertical direction, assuming that there is no variation in this direction. The result is shown in fig. 3, where the DOP profiles for three isolated stripes are displayed $(\mathrm{L}=6,10$ and $20 \mu \mathrm{m})$. The same trend is observed for the three stripes, however the positive edge peak is maximum for $\mathrm{L}=6 \mu \mathrm{m}$. The maximum DOP close to stripe edges is around $2 \%$, which corresponds to a differential linear deformation $\left(\varepsilon_{\mathrm{xx}}-\varepsilon_{\mathrm{zz}}\right)$ of approximately $3 \times 10^{-4}$.

We also mapped the DOP on cleaved cross sections of the reference samples, below the stripes. Fig. 4 displays the DOP and ROP maps below two isolated stripes $(\mathrm{L}=10$ and $20 \mu \mathrm{m})$. These results clearly reveal the deformation field induced by the $\mathrm{SiN}_{\mathrm{x}}$ stripes. The ROP maps show that some angular deformation is also present below the stripes.

To complete the picture for the reference samples, we did analytical modelling of the surface DOP profiles of fig. 3 using the concentrated edge force model (see e.g. [14]). More precisely, we assumed that at any point below the $\mathrm{SiN}_{\mathrm{x}}$ stripe, the stress tensor is mainly due to the film itself since there is a difference in thermal expansion coefficients between $\mathrm{SiN}_{\mathrm{x}}$ and InP. A second contribution is related to the two film edges. For any point away from the stripe, we only take into account the contribution from the film edges. The finite probing depth of the PL was introduced empirically by defining a quantized probed depth below the surface (this was an adjustable parameter). Finally, in order 
to reproduce the finite DOP that was measured close to stripe centers, we also had to assume that the effect of the difference in thermal expansion coefficients is anisotropic in the plane of the film even for $\mathrm{L}=20 \mu \mathrm{m}$ (we could check experimentally that this is no more the case for much larger stripes). The results of this fitting procedure are illustrated on fig. 5. The agreement is acceptable, given the limited number of adjustable parameters. Note that the positive and negative peaks near the edges derive from the singularities in the concentrated edge force. Geometrical discontinuities always induce singularities in the mechanical stresses.

Next we measured surface DOP maps after etching the InP and subsequent removal of the $\mathrm{SiN}_{\mathrm{x}}$ mask and edge walls passivation. Fig. 6 shows the vertical DOP averages for isolated etched ridges (L=6, 10 and $20 \mu \mathrm{m})$. Etch depth is $3 \mu \mathrm{m}$. The singularities near the edges are now more pronounced, but the curves retain the general shape of the DOP profiles on the reference sample. There is no more DOP inside the ridges. The DOP is very positive in the ridges close to edges, whereas it is negative in the etched areas close to the ridges. The magnitude of the DOP seems to be highest for $\mathrm{L}=20$ $\mu \mathrm{m}$.

Since the general shape is similar to that on the reference sample, we found it interesting to fit the curves with the same concentrated edge force model. The results are shown in fig. 7. The agreement is still acceptable.

As for the cross section observations, the cleavage quality was unfortunately too poor to get useful DOP maps in the case of etched samples.

In the second part of our study, we measured CL profiles on the very same etched samples, from the top surface only. Displayed on fig. 8 are CL profiles across different series on the etched sample (etched depth $3 \mu \mathrm{m}$ ), with $\mathrm{L}$ fixed at 1 $\mu \mathrm{m}$ and variable $\mathrm{S}$. The spectral shift on fig. 8 was obtained by subtracting to the measured CL peak positions the value determined on a reference wafer identical to the etched wafer, having seen no processing at all. One can see that the hydrostatic equivalent deformation within the ridge for $\mathrm{L}=1 \mu \mathrm{m}$ does not seem to depend significantly on the spacing $\mathrm{S}$. On the other hand, the amount of deformation in the spacings, in particular close to the ridges, seems to increase for decreasing $\mathrm{S}$ values. Positive peak shifts indicate a compressive equivalent deformation, whereas negative peak shifts indicates tensile deformation [13]. For spacings up to $S=1 \mu \mathrm{m}$, there is a close to ideal compensation between compressive deformation within the stripe and tensile deformation between stripes. For larger spacings, the tensile deformation near the ridge seems to relax as one goes away from the ridge. These observations are in overall agreement with the DOP measurements, although the details of the information derived from the two methods differ. In a first approximation, the CL curves have to be discussed in terms of the equivalent hydrostatic deformation while the DOP data are related to non-biaxial deformations in the plane of the measurement. DOP indicates compression in the ridges close to the edges, and tension outside (however due to the lower resolution in DOP we cannot resolve the profile for ridges with $\mathrm{L}<6 \mu \mathrm{m}$ ). Additional results on series with different spacings $\mathrm{S}$ (not shown here) also show that the DOP signal within the ridges with fixed $\mathrm{L}$ does not depend on the spacing $\mathrm{S}$, while the DOP in the spacings increases for smaller spacings. This is what we call the "cumulative" effect of nearby ridges.

On fig. 9 one can see the complementary trend to that of fig. 8: when the spacing $S=1 \mu \mathrm{m}$ is fixed, the amount of compressive deformation within the ridges is higher for narrower ridges. For broader ridges $(\mathrm{L}=6 \mu \mathrm{m})$ the deformation is relaxed near ridge center, a result totally in agreement with the DOP observation. Tensile deformation inside the spacings with $S=1 \mu \mathrm{m}$ appears not very dependent of the ridge width, except for $\mathrm{L}=0.5 \mu \mathrm{m}$.

Our observations with the two complementary techniques clearly show the presence of crystal deformation in and close to the etched features in InP. This might have a significant impact in the design and performances of photonic structures whose fabrication relies on etching of deep structures such as those investigated herein. Numerical fits with an analytical model based on the concentrated edge force model help getting an insight into the details of the deformation profiles. The next step will be the design of a model for the prediction of the deformation tensor at each point in the vicinity of the etched features, with some assumption about the physical origin of the mechanical deformation. Such a tool would be helpful for photonic circuit designers.

Acknowledgments

A. Torres and J. Jiménez were funded by Junta de Castilla y León (Grants VA293U13 and VA081U16)

\section{REFERENCES}

[1] T. R. Hayes, U. K. Chakrabarti, F. A. Baiocchi, A. B. Emerson, H. S. Luftman, and W. C. Dautremont-Smith, J. Appl. Phys. 68, 785 (1990).

[2] M. Heinbach, J. Kaindl, and G. Franz, Appl. Phys. Lett. 67, 2034 (1995).

[3] J. Etrillard, F. Héliot, P. Ossart, M. Juhel, G. Patriarche, P. Carcenac, C. Vieu, M. Puech, and P. Maquin, J. Vac. Sci. Technol. A 14, 1056 (1996). 
[4] M. Rahman, J. Appl. Phys., 82, 2215 (1997).

[5] D. L. Green, E. L. Hu, P. M. Petroff, V. Liberman, M. Nooney, and R. Martin, J. Vac. Sci. Technol., B 11, 2249 (1993).

[6] C.-H. Chen, D. G. Yu, E. L. Hu, and P. M. Petroff, J. Vac. Sci. Technol., B 14, 3684 (1996).

[7] M. Rahman, L. G. Deng, C. D. W. Wilkinson, and J. A. van den Berg, J. Appl. Phys. 89, 2096 (2001).

[8] J.P. Landesman, J. Jiménez, C. Levallois, F. Pommereau, C. Frigeri, A. Torres, Y. Léger, A. Beck, and A. Rhallabi, J. Vac. Sci. Technol., A 34, 041304-1 (2016).

[9] G. Morello, M. Quaglio, G. Meneghini, C. Papuzza, and C. Kompocholis, J.Vac. Sci. Tech. B 24, 756 (2006).

[10] D. T. Cassidy, S. K. K. Lam, B. Lakshmi, and D. M. Bruce, Appl. Opt. 43(9), 1811 (2004).

[11] M. L. Biermann, D. T. Cassidy, T. Q. Tien, and J. W. Tomm, J. Appl. Phys. 101, 114512-1 (2007).

[12] M. Avella, J. Jiménez, F. Pommereau, J. P. Landesman, and A. Rhallabi, Appl. Phys. Lett. 93, 131913-1 (2008).

[13] G.D. Pitt, Solid State Comm. 8, 1119 (1970).

[14] S.M. Hu, J. Appl. Phys. 57, 4661 (1979).

[15] S. P. Timoshenko and J. N. Goodier, Theory of Elasticity, 3rd edn. (McGraw-Hill, New York, 1970).

[16] I. De Wolf, H. Maes, and S.K. Jones, J. Appl. Phys. 79, 7148 (1996). 
Fig. 1: Color scale maps of the DOP, ROP and PL yield for the reference sample $\left(10 \mu \mathrm{m}\right.$ wide $\mathrm{SiN}_{\mathrm{x}}$ stripe at the (100) surface of InP). Measurements are along the normal to the (100) surface. Values for the DOP and ROP are indicated in $\%$ on the color scale to the right of each map. PL yield is given in counts (color scale to the right of the corresponding map).

Fig. 2: CL spectrum on a reference wafer (red dash line) and average of the spectra in etched stripes $\mathrm{L}=1 \mu \mathrm{m}$ with different spacings (blue; etched depth $3 \mu \mathrm{m}$ ).

Fig. 3: DOP curves obtained from averaging the maps such as the one on fig. 1 along the length of the $\mathrm{SiN}_{\mathrm{x}}$ stripes, for width $20 \mu \mathrm{m}$ (black), $10 \mu \mathrm{m}$ (red) and $6 \mu \mathrm{m}$ (dash blue).

Fig. 4: Color scale maps of the DOP and ROP for the reference sample, for measurements perpendicular to the cleaved cross section. DOP and ROP values are indicated in \% on the color scale bars. $20 \mu \mathrm{m}$ stripe: DOP (a), ROP (b); $10 \mu \mathrm{m}$ stripe: DOP (c), ROP (d).

Fig. 5: Analytical fits with the edge force model to the DOP profiles for 10 (a) and $20 \mu \mathrm{m}$ (b) stripes on the reference sample. Blue curves: experimental data; red dash curves: model.

Fig. 6: Average DOP curves on isolated ridges of the etched sample (etched depth $3 \mu \mathrm{m}$ ), for width $20 \mu \mathrm{m}$ (black), 10 $\mu \mathrm{m}$ (red) and $6 \mu \mathrm{m}$ (dash blue).

Fig. 7: Analytical fits with the edge force model to the DOP profiles for 10 (a) and $20 \mu \mathrm{m}$ (b) isolated ridges on the etched sample (etch depth $3 \mu \mathrm{m}$ ). Blue curves: experimental data; red dash curves: model.

Fig. 8: CL spectral shift (difference between peak position measured on the etched sample and on a reference wafer) from the surface of the etched sample (etched depth $3 \mu \mathrm{m}$ ) for series with line width $\mathrm{L}=1 \mu \mathrm{m}$ and different spacings $\mathrm{S}$. Black $\boldsymbol{\square}: \mathrm{S}=0.5 \mu \mathrm{m}$; Red $\boldsymbol{\Delta}: \mathrm{S}=1 \mu \mathrm{m}$; Green $\downarrow: \mathrm{S}=2 \mu \mathrm{m}$; Blue $\mathrm{X}: \mathrm{S}=3 \mu \mathrm{m}$; Pink + : $\mathrm{S}=6 \mu \mathrm{m}$; Grey $\star: \mathrm{S}=12 \mu \mathrm{m}$; Light blue curve: isolated line $\mathrm{L}=1 \mu \mathrm{m}$.

Fig. 9: CL spectral shift measured from the surface of the etched sample (etched depth $3 \mu \mathrm{m}$ ) for series with different line widths $\mathrm{L}$ and spacing $\mathrm{S}=1 \mu \mathrm{m}$. Blue $\diamond: \mathrm{L}=6 \mu \mathrm{m}$; Red $\mathbf{\square}: \mathrm{L}=1 \mu \mathrm{m}$; Black $\boldsymbol{\Delta}$ : $\mathrm{L}=0.5 \mu \mathrm{m}$. 


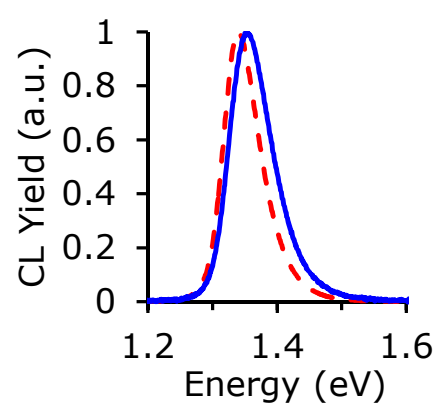

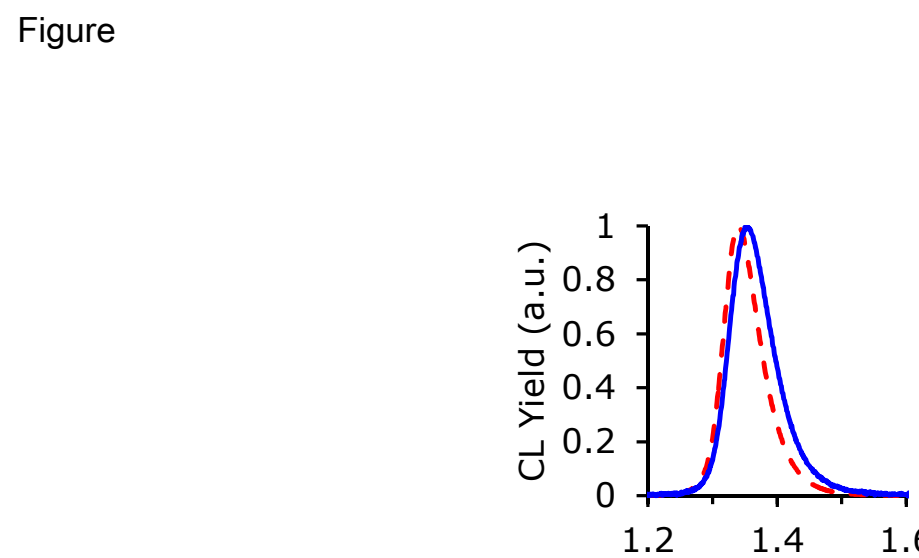
Energy (eV) 
Figure

Click here to download Figure Fig 3.eps $\stackrel{ \pm}{ }$

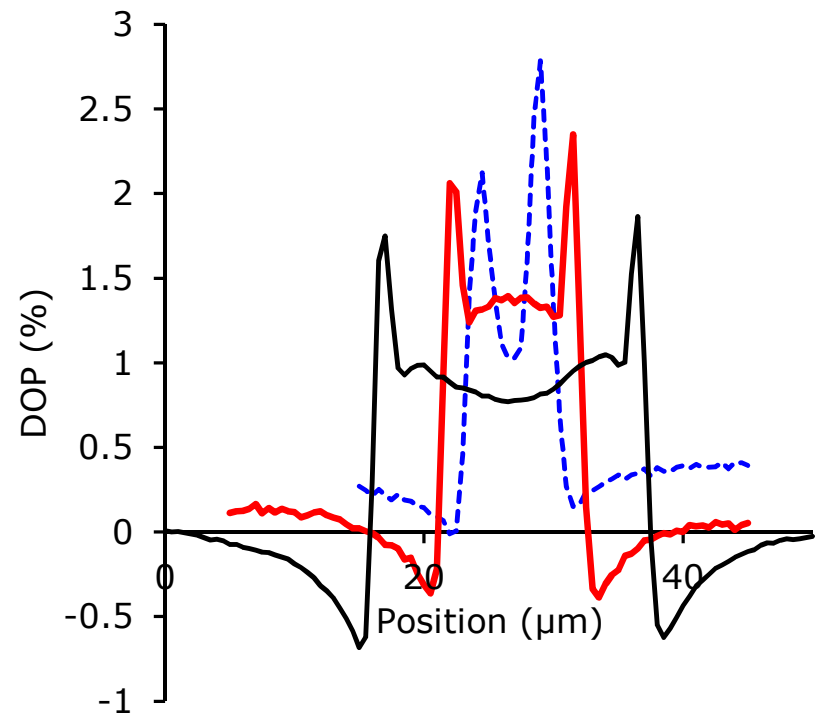




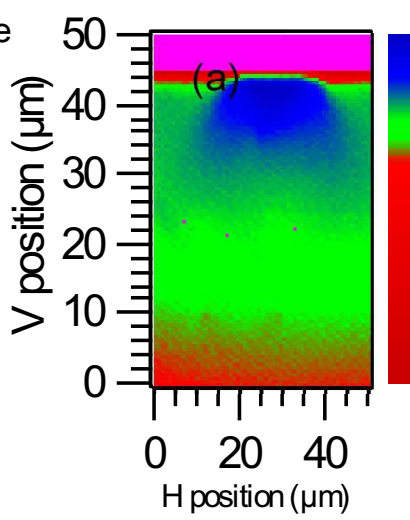

$-2$
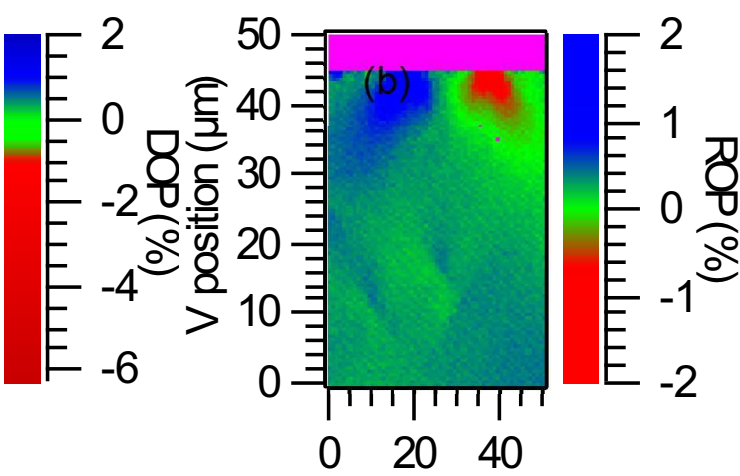

$\mathrm{H}$ position $(\mu \mathrm{m})$

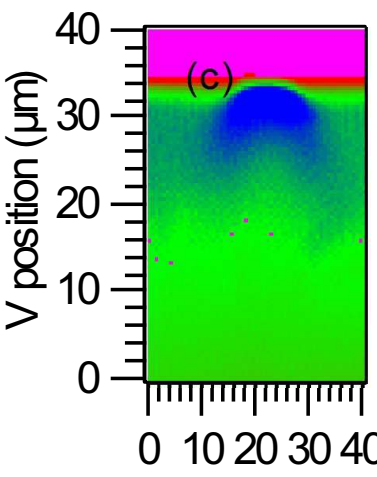

$\mathrm{H}$ position $(\mu \mathrm{m})$

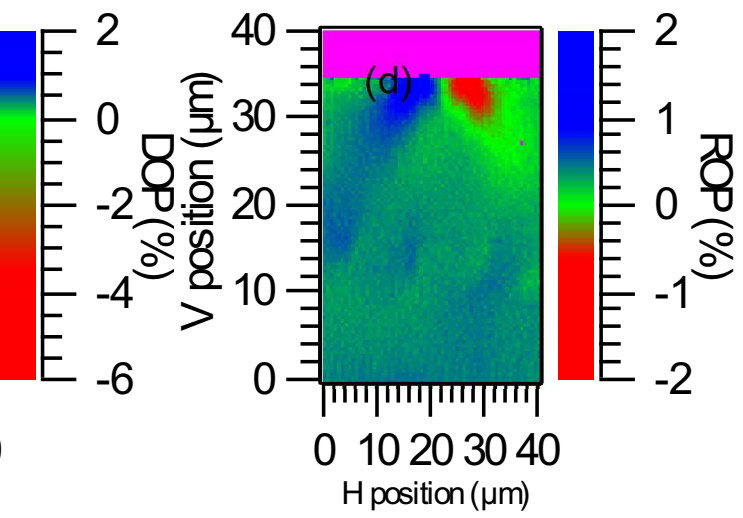


Click here to download Figure Fig 5-a.eps $\underline{\underline{ }}$

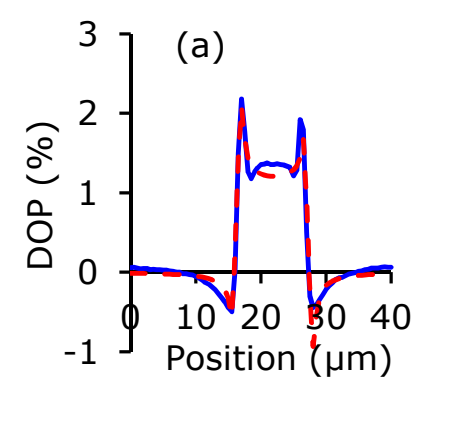

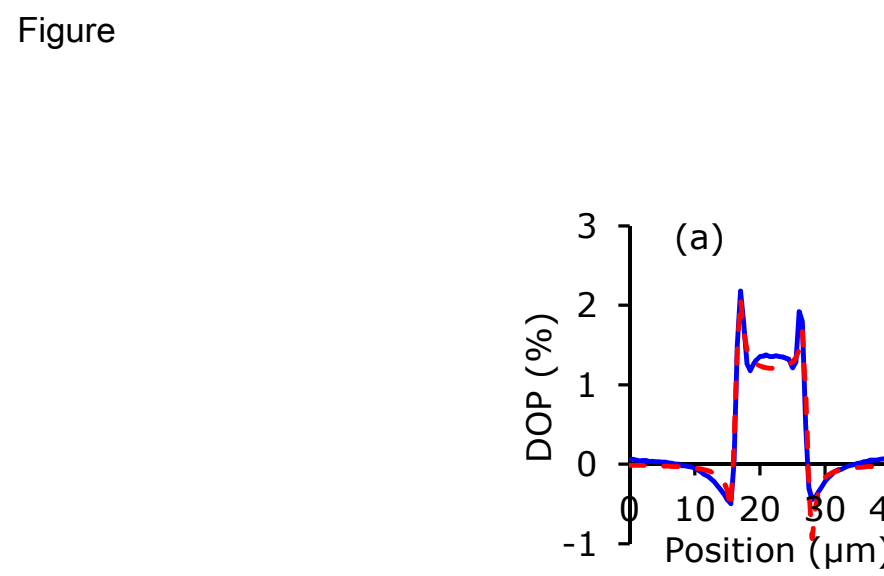

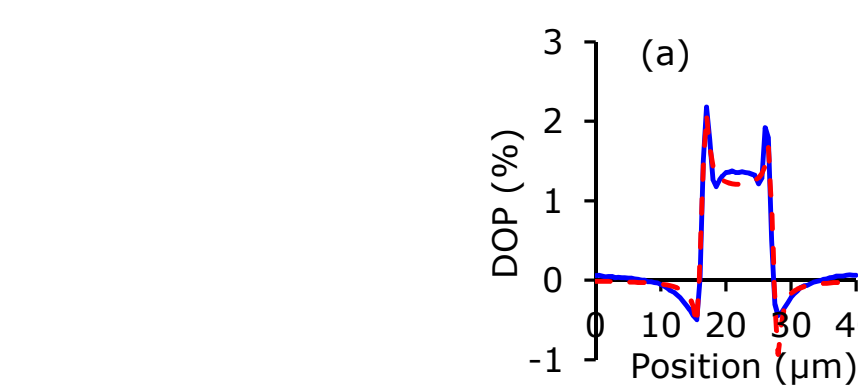

0

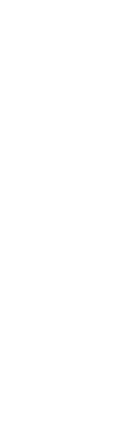
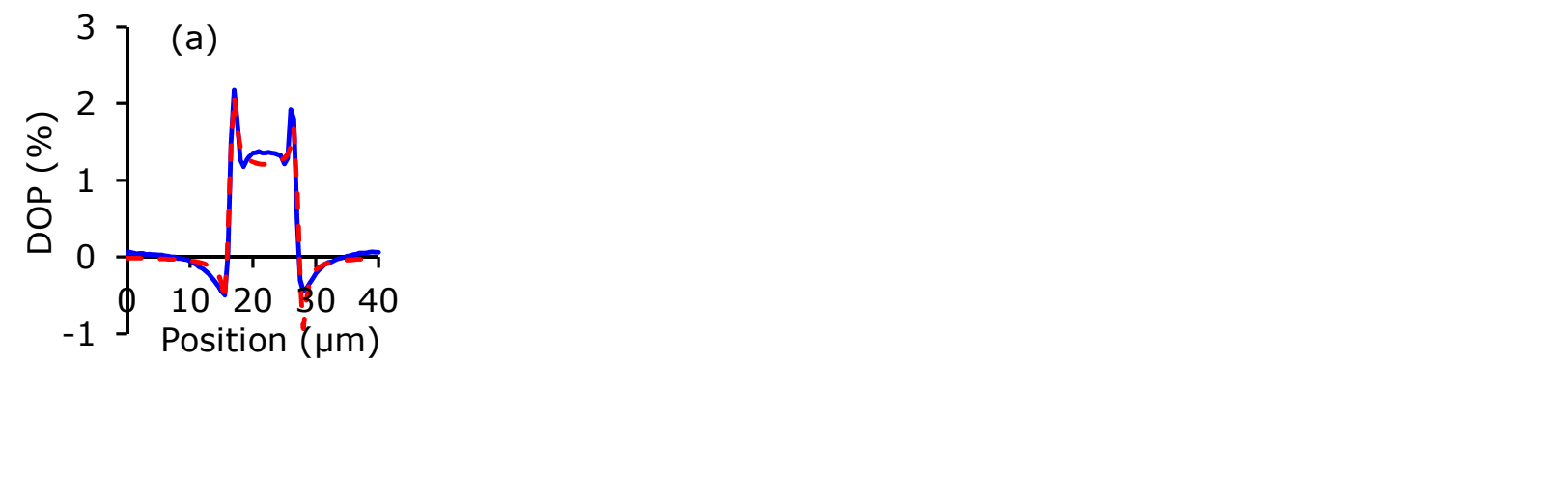

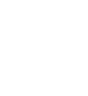

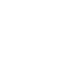

(2)

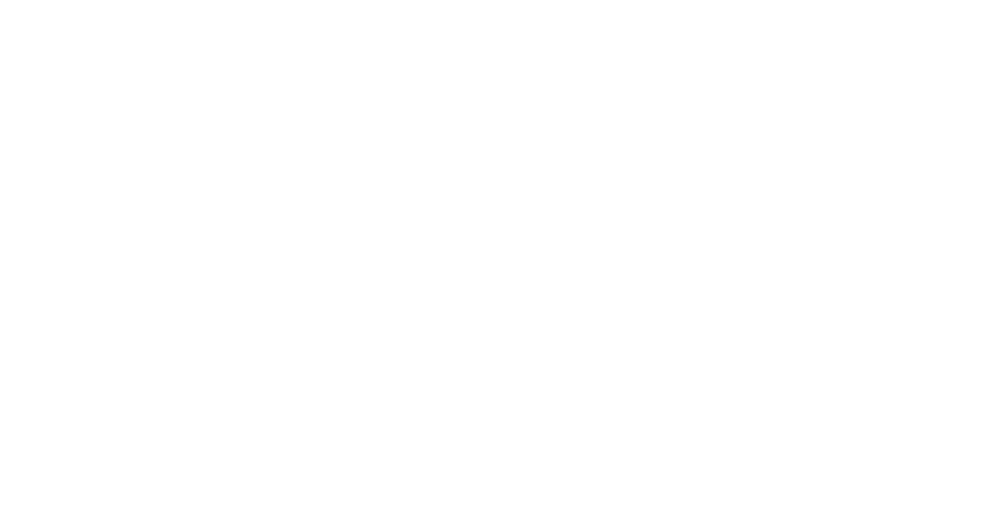

(1)

C

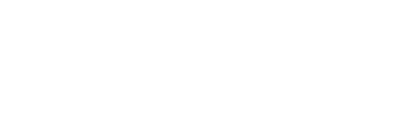


Click here to download Figure Fig 9.eps $\underline{\underline{ }}$

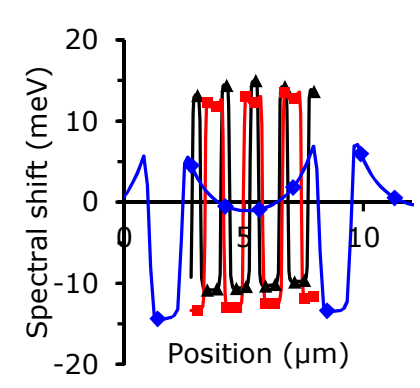

